\title{
Numerical Study on the Effect of Grouting on Long-Term Settlement of Tunnels in Clay
}

\author{
Dong-Mei Zhang, Hong-Wei Huang, and Jian-Ming Wang \\ Department of Geotechnical Engineering, Tongji University, Shanghai 200092, China \\ dmzhang@mail.tongji.edu.cn
}

\begin{abstract}
The long-term settlements over tunnels can be rather significant, particularly when tunnels are embedded in soft and compressible soils. The influence of grouting on the evolution of long-term surface settlement, as well as ground loss, is simulated by imposing prescribed volumetric strain on the disturbed area around the tunnel due to shield tunneling. The volumetric strain could be detected from the grouting ratio of grouting volume and the volume of the physical gap of shield tunnel. Finally, some conclusions are drawn from the numerical simulations.
\end{abstract}

Keywords: Grouting, Tunnel, Long-term settlement, Prescribed volumetric strain.

\section{Introduction}

Many field observations on long-term settlements of tunnels have indicated that the long-term settlements can be significant when tunnels are embedded in soft and compressible soils regardless of the tunneling methods ([1], [2], [3], [4], [5], [6]). [7] reported that this kind of long-term settlement might last two or more years in saturated soft ground even without any surface loading for Shanghai urban subway tunnel. The surface settlement of Shanghai metro tunnel line 2 almost doubled in three months after the tunnel construction ([2]). Based on comprehensive field data, [4] concluded that typically the increase in settlements over long-term is of the order of $30 \%-90 \%$ of the total settlement. This is confirmed, for example, by the observed settlements over a period of 11 years reported by [6] for a $3 \mathrm{~m}$ diameter tunnel constructed in normally consolidated silty clay in Grimsby, England. The final equilibrium of settlement was achieved after about 10 years.

[1] concluded that the major factors influencing the development of postconstruction settlements above tunnels could be attributed to the followings. 1.The magnitude and distribution of excess pore pressure due to shield tunneling; 2.The compressibility and permeability of the soil; 3.The drained conditions of the tunnel lining relative to the permeability of the surrounding soils; 4 .The initial pore pressure distribution prior to the tunnel construction;

These four factors indicate that the long-term behaviour is, to some extend, the extension of the short-term behaviour of the tunnel in terms of ground movements due to tunneling. In all the related studies with regard to the long-term behaviour of 
tunnels, the effect of grouting on the development of long-term behaviour is omitted for simplification. However, [4] pointed out that the effects of grouting around tunnel linings deserves more attention than it has generally been given and its influence on settlement must be taken into account when the detailed long-term behaviour of tunnel is studied numerically. The field-based measurement from Shanghai metro tunnel line-2 also confirms that the effect of grouting on the excess pore pressure is quite remarkable and not reasonable for neglecting ([2]). [9] studied the effectiveness of grouting on tunnels in clay during long-term through field trial, laboratory test combined with numerical simulations. However, only settlements over tunnels were considered.

Consequently, the influence of grouting on the long-term behaviour of tunnels in clay is simulated using FEM code of Plaxis in terms of the development of surface settlement and ground loss, which are usually used to predict the influence of the shield tunneling on the surrounding environment.

\section{Numerical Modelling}

The numerical modelling is carried out based on Shanghai No.2 metro tunnel. The tunnel lining is simulated using linear elastic model and is simplified as elastic beam in numerical modelling. Elasto-plastic model of Mohr-Coulomb is adopted for soft soils. The numerical simulation is performed with 15-node isoparametric finite elements under the assumption of plane strain conditions. The tunnel lining for Shanghai metro line No. 2 is $6.2 \mathrm{~m}$ in external diameter and $5.5 \mathrm{~m}$ in internal diameter. The average depth to the center-line of the tunnel is about 1.8D ( $\mathrm{D}$ is the tunnel diameter). The tunnel was excavated by EPB shield machine. The shield body is $6.24 \mathrm{~m}$ long with $6.34 \mathrm{~m}$ in diameter. Correspondingly, the clearance between the external diameters of shield body and the tunnel, which is usually named physical gap $G_{p}$ according to the definition of [2], will reach 140mm. Correspondingly, the FEM mesh of the tunnel is shown in Fig.1 combined with soils distribution. The symmetry of the model is considered in the simulation. The width of the numerical model is $40 \mathrm{~m}$, which is 6.5 times as wide as the external diameter of the tunnel. The vertical dimension is $36 \mathrm{~m}$, which is about 3 times the depth of the external diameter of the tunnel.

\subsection{Simulation of Grouting}

The grouting in shield tunnel plays a very important role to decrease the closure of the tail void and the surface settlement over tunnels in result. The influence of grouting is usually simulated by exerting a uniform pressure on the tunnel lining in references. However, it is quite difficult to determine the magnitude and distribution of the grouting pressure since their fluctuations during construction. Meanwhile, the volume of the grouting is stable and very easy to obtain. The volume of grouting denoted as $V_{\text {grout }}$ could be defined in terms of grouting ratio $R$ and the volume of physical gap $V_{\text {gap }}$ shown as equation (1).

$$
V_{\text {grout }}=R \cdot V_{\text {gap }} .
$$


Here, $V_{\text {grout }}$ is the volume of grouting during shield tunneling. $V_{\text {gap }}$ means the volume of physical gap. The volume of physical gap studied in this paper is $1.38 \mathrm{~m}^{3} / \mathrm{m} . R$ represents the grouting ratio.

Actually, the grouting will inevitably result in the expansion of the soils in a disturbed area around the tunnel when $R$ is larger than 1.0. As a result, the effect of grouting could be simulated by imposing a prescribed volumetric strain on the disturbed area around the tunnel. The disturbed area is assumed to be a homocentric circle with the tunnel, which is of $10 \mathrm{~m}$ in diameter based on the in-situ observation. Then the disturbed area $V_{d i s}$ reaches $48.32 \mathrm{~m}^{3} / \mathrm{m}$. Correspondingly, the prescribed volumetric strain could be presented by equation (2).

$$
\varepsilon_{v}=(R-1) \cdot V_{g a p} / V_{d i s}=2.85 \cdot(R-1)(\%) .
$$

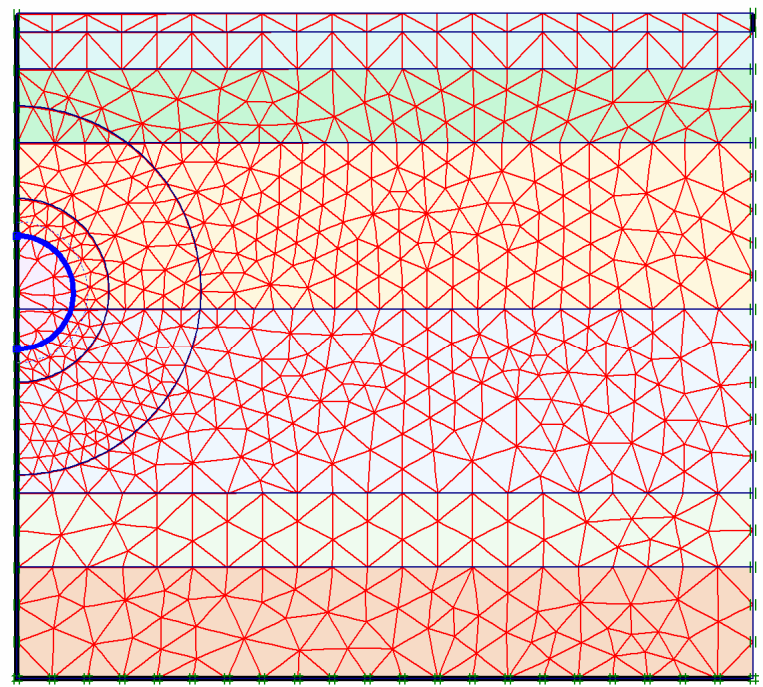

Fig. 1. FEM mesh in numerical simulation

\subsection{Boundary Conditions}

The boundary conditions in the numerical simulation contain the following two types, one is the displacement boundary condition, and the other is the drainage condition. A free displacement boundary condition is adopted at the ground surface. It is assumed that no horizontal nor vertical displacement takes place at the lower boundary, for it is beyond the influence of tunnel construction. The lateral displacements at left- and right-hand boundary are both fixed as zero. The left-hand boundary is the line of symmetry. The drainage condition at the ground surface is assumed to be free; meanwhile the lower boundary as well as the left-hand boundary condition is considered to be impermeable, in order to prevent the pore pressure dissipation across 
the boundary during the settlement development. However, the right-hand boundary is taken as permeable during the long-term settlement.

The initial effective stresses and hydrostatic pore pressure are calculated based on the weight of the soil and the underground water condition.

\subsection{Parameters Used in Numerical Modeling}

The parameters involved in the numerical analysis are listed in Table 1and Table 2

Table 1. Characteristics of soils of Shanghai

\begin{tabular}{llllll}
\hline $\begin{array}{l}\text { Depth } \\
(\mathrm{m})\end{array}$ & $\begin{array}{l}\text { Young's } \\
\text { modulus } E \\
(\mathrm{MPa})\end{array}$ & $\begin{array}{l}\text { Poisson's } \\
\text { ratio } \boldsymbol{V}\end{array}$ & $\begin{array}{l}\text { Bulk } \\
\text { density } \gamma \\
\left(\mathrm{kN} / \mathrm{m}^{3}\right)\end{array}$ & $\begin{array}{l}\text { Cohesion } \\
\boldsymbol{c}(\mathrm{kPa})\end{array}$ & $\begin{array}{l}\text { Friction } \\
\text { angle } \\
\left(\mathrm{o}^{\circ}\right)\end{array}$ \\
\hline $0 \sim 3$ & 2.395 & 0.35 & 18.7 & 13 & 14.8 \\
$3 \sim 7$ & 2.032 & 0.35 & 18.0 & 7 & 18.7 \\
$7 \sim 16$ & 1.293 & 0.35 & 17.0 & 10 & 9.8 \\
$16 \sim 26$ & 3.000 & 0.35 & 18.3 & 10 & 19.1 \\
$26 \sim 30$ & 4.216 & 0.35 & 19.9 & 30 & 12.8 \\
$30 \sim 36$ & 6.560 & 0.35 & 20.1 & 6 & 26.3 \\
\hline
\end{tabular}

Table 2. Parameters of tunnel lining

\begin{tabular}{lll}
\hline$E A(\mathrm{kN} / \mathrm{m})$ & $E I\left(\mathrm{kN} \cdot \mathrm{m}^{2} / \mathrm{m}\right)$ & Poisson's ratio $\boldsymbol{V}$ \\
\hline $1.2 \mathrm{e} 7$ & $1.2 \mathrm{e} 5$ & 0.15 \\
\hline
\end{tabular}

\subsection{Numerical Simulation Procedure}

The influence of grouting on the long-term settlement was simulated using 4 consecutive steps. The 4 consecutive steps correspond to different stages of the development of surface settlement over tunnels. STEP 0 means the initial state of the ground before taking account of the influence of tunneling. STEP 1 represents the tunnel construction. The effect of grouting is modeled in STEP 2 by imposing the prescribed volumetric strain on the disturbed area. STEP 3 is the final case in the simulation, where the long-term settlement occurs due to the consolidation of the soil. The numerical results for each step are the initial state of the next step since the 4 steps are consecutive both in time and stress state.

The prescribed volumetric strains adopted in STEP2 are 0\%, 0.5\%,1\%, 2\%, 3\% and $4 \%$. They are corresponding to the grouting ratios of $1,1.17,1.35,1.7,2.05$ and 2.4 respectively. The volume of grouting is usually much larger than that of physical gap considering the over-excavation during shield tunneling. Correspondingly, the grouting ratios $R$ with a scale of 1 to 2.4 are adopted in the numerical simulation.

\section{Influence of Grouting on the Long-Term Settlements}

The evolutions of long-term surface settlements over tunnels with 6 different grouting ratios are presented in Fig.2 and Fig.3. The surface settlement in Fig.2 involves the short-term settlement and therefore is the total settlement. 


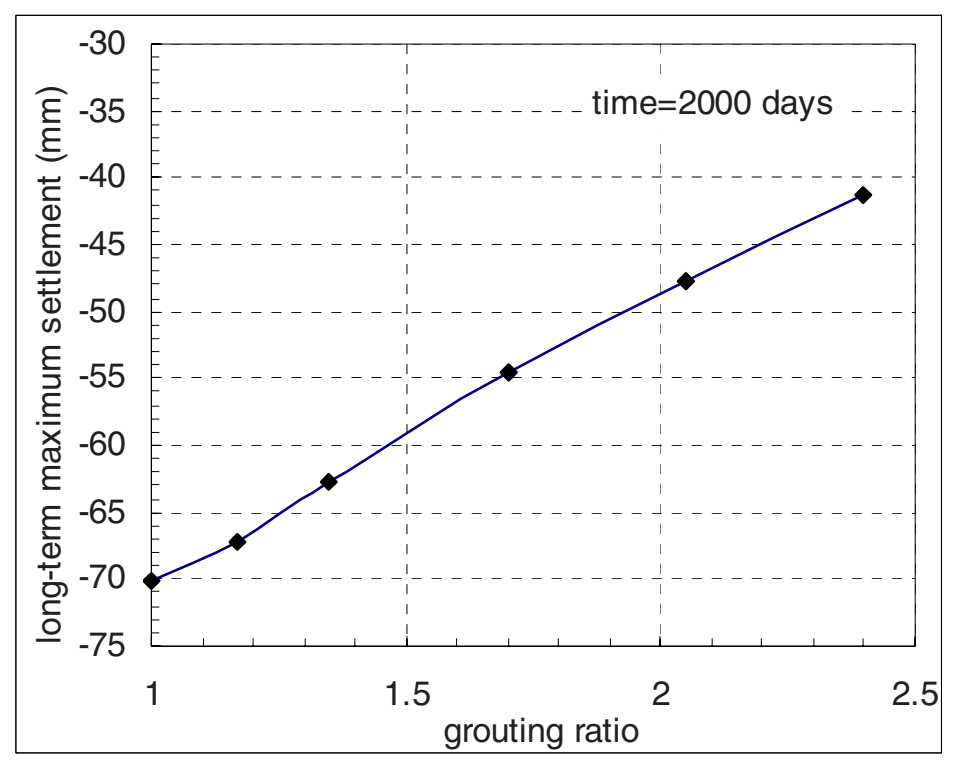

Fig. 2. Development of long-term maximum surface settlement with grouting ratio

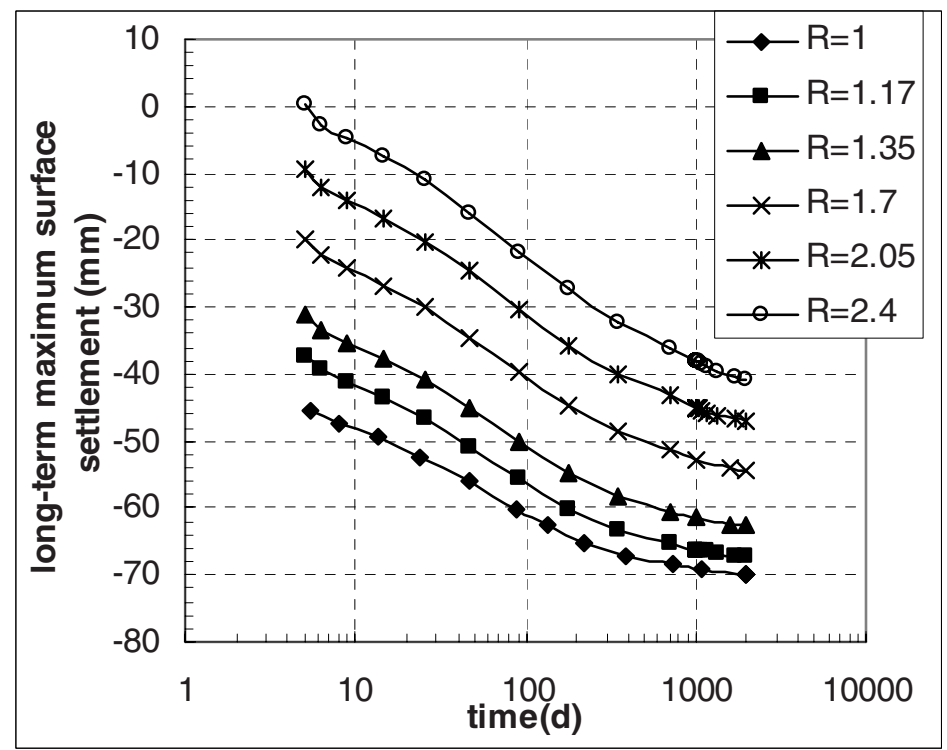

Fig. 3. Evolution of long-term maximum surface settlement with different grouting ratios

Fig.2 and Fig.3 reveal that the magnitude of maximum surface settlement is smaller at any time with a higher grouting ratio. The maximum long-term settlement almost decreases $42 \%$ with the grouting ratios increase from 1 to 2.4 at 2000 days 
after grouting. However, it could be found that higher grouting ratio results in higher post-grouting settlements from the different slopes of the curves in Fig. 3 due to the higher pore pressure caused by grouting. Therefore, it takes more time for the longterm settlement to reach the stability for the case with higher grouting ratios.

The development of ground loss normalized to the area of the cross section of tunnel with grouting ratio is presented in Fig. 4. The normalized ground loss can be described by equation (3).

$$
V / V_{t}=\sqrt{2 \pi} i S_{\max } / \pi r^{2}(\%) .
$$

Here $S_{\max }$ means the maximum surface settlement, $r$ is the external diameter of shield machine. $i$ is the width of surface settlement trough and could be determined by Peck's empirical formulation (equation 4) ([8]).

$$
S(x)=S_{\max } \exp \left(-x^{2} / 2 i^{2}\right) .
$$

Here, $x$ is the distance from studied point to the tunnel centre.

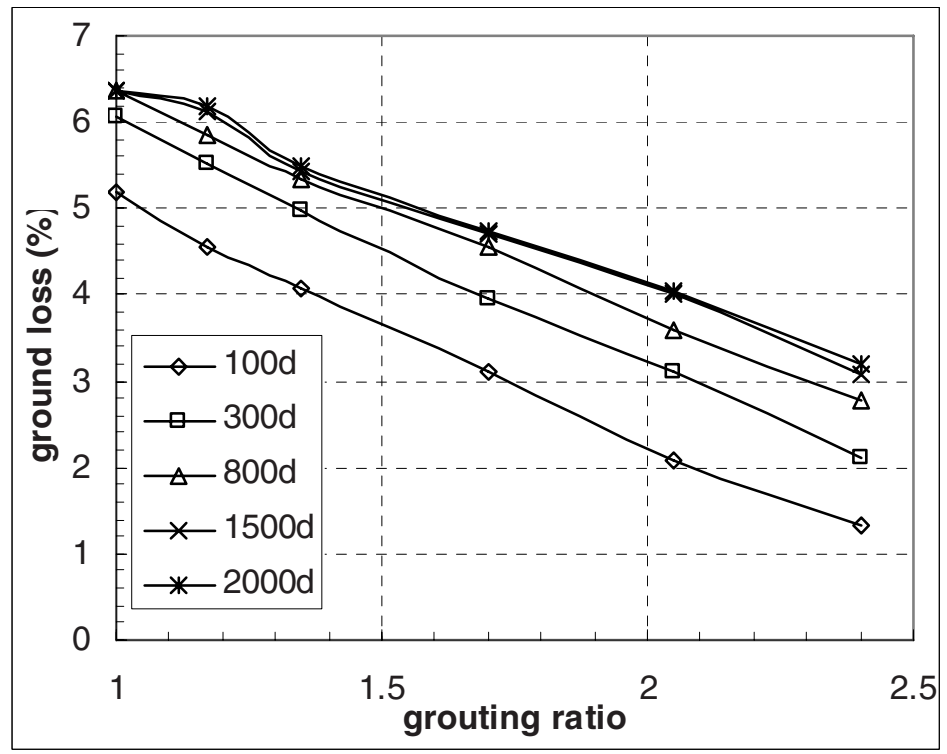

Fig. 4. Evolution of ground loss with grouting ratio

It can be clearly found from Fig.4 and Fig.5 that ground loss continuously decrease with grouting ratio and increases with time until it reaches the stability. The evolution of ground loss with time corresponding to different grouting ratio is similar with that of the long-term maximum surface settlement. 


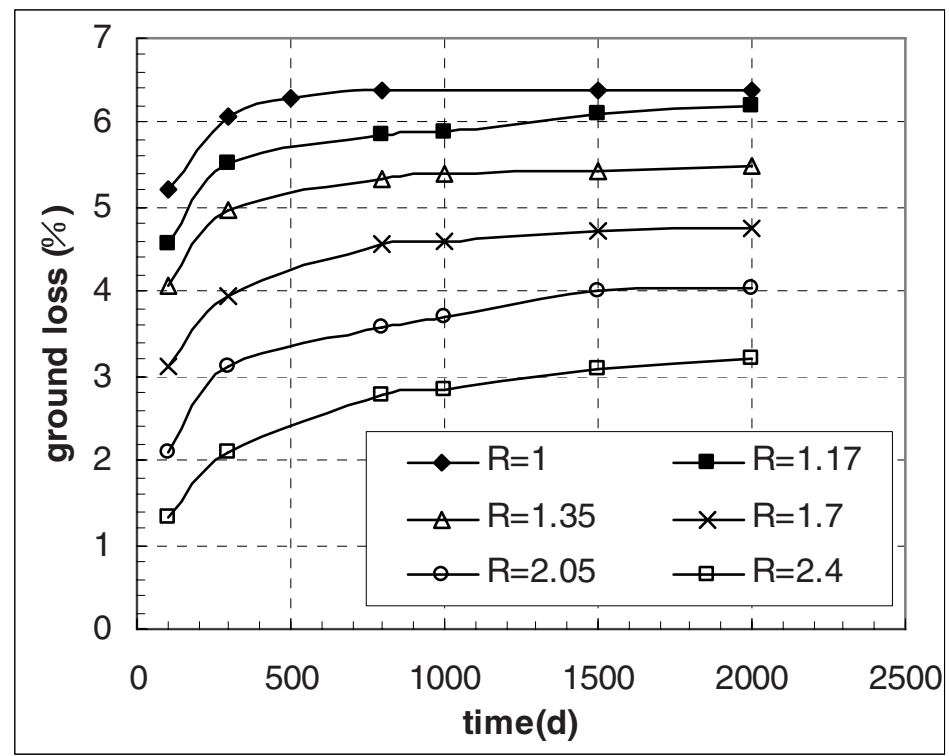

Fig. 5. Evolution of ground loss with time

\section{Conclusions}

The grouting effect is simulated by imposing prescribed volumetric strain on the disturbed soils around the tunnel. The evolution of long-term settlement of tunnels in clays is studied and the following conclusions are obtained.

1. It is feasible and reasonable to simulate the grouting effect with the prescribed volumetric strain of the disturbed area. However, there is a lack of in-situ measurement to validate the numerical simulation.

2. The long-term settlement as well as the ground loss decreases significantly with grouting. While the post-grouting settlement and ground loss increase with the grouting ratio due to the higher pore pressure caused by the higher grouting ratios.

3 . The evolution of surface settlement and ground loss with time is remarkable regardless of the grouting ratios.

Acknowledgments. The authors wish to acknowledge the financial support from National Natural Science Foundation of China (No. 50608058).

\section{References}

1. Mair, R. J., Taylor, R. N.: Theme lecture: Bored tunneling in the urban environment. Proceedings of the Fourteenth International Conference on Soil Mechanics and Foundation Engineering, (1997) 2353-2385

2. Lee, K. M., Ji, H. W., Shen, C. K., Liu, J. H., Bai, T. H. : Ground Response to the Construction of Shanghai Metro Tunnel-Line 2. Soils and Foundations, 39(3). (1998) 113-134 
3. Shirlaw, J. N.: Pore pressure around tunnels in clay: 1 Discussion. Canadian Geotechnical Journal 30, (1993) 1044-1046

4. Shirlaw, J. N.: Observed and calculated pore pressures and deformations induced by an earth balance shield: Discussion 1. Canadian Geotechnical Journal 32, (1995) 181-189

5. Cooper, M. L., Chapman, D. N., Rogers, C. D. and Chan, A. H.: Movements in the Piccadilly Line tunnels due to the Heathrow Express construction. Géotechnique, 52(4). (2002) 243-257

6. O'Reilly, M. P., Mair, R. J., Alderman, G. H.: Long-term settlements over tunnels: an eleven-year study at Grimsby. Proceedings of Conference Tunneling, London, Institution of Mining and Metallurgy, (1991) 55-64

7. Hou, X., and Zhou, Z.: Saturated ground movement due to shield tunneling. Proceedings of the International Conference of International Tunneling Association, Madrid, Spain. (1988) 351-356

8. Peck, R. B.: Deep excavation and tunneling in soft ground. Proceeding 7th International Conference on Soil Mechanics and Foundation Engineering, 3. (1969) 1469-1472

9. Komiya, K. Soga, K. Akagi, H. Jafari, M.R. and Bolton, M.D.: Soil consolidation asssociated with grouting during shield tunneling in soft clayed ground. Geotechnique, 51(10). (2001) 835-846 